\title{
DE LA PRODUCCIÓN AL USO: TECNOLOGÍA DE HOJAS EN EL SITIO CUEVA MARIPE (SANTA CRUZ, ARGENTINA)
}

\author{
FROM PRODUCTION TO USE: BLADE TECHNOLOGY AT CUEVA MARIPE \\ SITE (SANTA CRUZ, ARGENTINA)
}

\author{
Virginia Lynch ${ }^{1}$ y Darío Hermo ${ }^{1}$
}

\begin{abstract}
La tecnología de hojas ha sido reconocida en varias localidades arqueológicas de Patagonia, principalmente en contextos del Holoceno Medio y Tardío. Numerosos autores han afrontado el estudio de estas tecnologías entendiéndolas como formas de aprovechamiento de materias primas tendiente a la optimización. Sin embargo, la producción y uso de hojas muchas veces implica otras decisiones más allá de la disponibilidad de materias primas en un área determinada.

En el sitio Cueva Maripe (provincia de Santa Cruz, Argentina) fueron registrados artefactos correspondientes a la totalidad de la cadena operativa de la producción de hojas. Por lo tanto, el siguiente trabajo tiene por objetivo analizar las evidencias de los distintos pasos en la manufactura de esta tecnología durante el lapso ocupacional del Holoceno Medio, desde la preparación del núcleo hasta su uso y descarte.

Dado que a lo largo del Macizo del Deseado abundan rocas de buena calidad para la talla, la producción de hojas en Cueva Maripe no estaría dirigida hacia una estrategia de maximización de materias primas. Los resultados obtenidos del análisis tecnomorfológico y funcional permiten sostener que la confección de dichas piezas estaría relacionada con un determinado modo de producción y con diseños orientados a una multiplicidad de usos (trabajo sobre material blando, madera y hueso).
\end{abstract}

Palabras claves: tecnología de hojas, análisis funcional, Holoceno Medio, Patagonia meridional.

Blade technology has been recovered at several archaeological sites in Patagonia, mainly in Middle and Late-Holocene contexts. Many authors define this technology as ways of raw materials exploitation with the purpose of optimization. However, blade production and use often involves other decisions beyond the availability of raw materials in a particular area.

At the Cueva Maripe site (Santa Cruz Province, Argentina), artefacts corresponding to the entire operative chain of blade production were recovered. The main objective of this paper is to analyse the evidence of these different stages in the blade production process, from core preparation until its use and discard, during the Mid-Holocene occupation at Cueva Maripe site.

Since rocks of good quality for carving are abundant in the Deseado Massif of Santa Cruz, blade production at Cueva Maripe site would not have been directed towards the maximization of raw materials. The results of the techno-morphological and functional analysis of this technology at the site support the view that blade manufacture would have been related to a particular production mode, with designs oriented to a diverse range of uses on soft and hard materials such as hide, wood and bone.

Key words: Blade technology, micro-wear analysis, Mid-Holocene, Patagonia.

El marco ambiental de Patagonia ha sido muy variable desde fines del Pleistoceno y durante gran parte del Holoceno. El Óptimo Climático se alcanzó entre los ca. 8.500-5.500 años a.p. (Rabassa 2010), y si bien pueden detectarse algunos reavances glaciarios (neoglaciaciones), el cambio respecto del Pleistoceno Final fue profundo. Consecuentemente, el Holoceno Medio (desde ca. 7.500 años a.p. hasta ca. 3.000 años a.p.) se caracterizó por condiciones más secas y cálidas que las actuales, sumado al desarrollo de una estepa arbustiva (Coronato et al. 1999).

Durante el Holoceno Medio en Patagonia meridional se observaron estos cambios ambientales como así también culturales en diferentes sectores de la meseta central de Santa Cruz (Argentina) (Miotti y Salemme 2004). En este marco (ca.7.500 a 3.000 años a.p.), se incorporaron ciertas innovaciones en la producción tecnológica, como los líticos para las boleadoras y la recurrencia de hojas o formas laminares como soportes para la manufactura de instrumentos (Aschero 1987).

El estudio de la producción de hojas en diferentes sectores de Patagonia ha sido el foco de interés en varias investigaciones (Aschero et al. 1992-93; Hermo 2008; Hermo y Magnin 2012; Paunero et al. 2007). La predominancia de estas en los conjuntos ha sido interpretada como parte del acervo cultural de la Industria Casapedrense

1 CONICET, División Arqueología, Facultad de Ciencias Naturales y Museo (UNLP). Paseo del Bosque S/N, La Plata (1900), Buenos Aires, Argentina. lynchvirginia@gmail.com; dhermo@fcnym.unlp.edu.ar 
(ca. 7.260 años a.p.) caracterizada por hojas con o sin retoques, raspadores de morfologías alargadas, escasos cuchillos y raederas, boleadoras y ausencia de puntas triangulares (Cardich et al. 1973; Cardich y Flegenheimer 1978; Menghin 1952). Asimismo en el Río Pinturas, al oeste del Macizo del Deseado, Gradín et al. (1979) definen un nivel arqueológico cultural denominado Río Pinturas II (desde ca. 7.000 a 3.400 años a.p.) que evidenciaría una coexistencia entre la Industria Toldense y Casapedrense. Estudios posteriores han propuesto la existencia de tradiciones culturales patagónicas (p.ej. Tradición Río Pinturas y Tradición Central Patagónica); que, en mayor o menor medida, utilizaron técnicas de extracción de hojas para la fabricación de su instrumental (Aschero 1987).

En la actualidad, nuevas investigaciones desarrolladas en el Macizo del Deseado (provincia de Santa Cruz), específicamente en las localidades La Primavera (LP) y La María (LM), han generado importantes aportes al estudio de esta tecnología del Holoceno (Hermo y Lynch 2015; Lynch y Hermo 2015; Paunero et al. 2007; Skarbun 2009).

En el presente trabajo se toma como referencia los conjuntos artefactuales del sitio arqueológico Cueva Maripe, ubicado en una de las mencionadas localidades (LP), donde se registró un incremento en las evidencias líticas relacionadas con las técnicas extractivas de hojas y su utilización como formas bases durante el bloque temporal del Holoceno Medio (Hermo 2008; Lynch 2016). Con el fin de evaluar las posibles causas relacionadas con la producción de estos soportes laminares y su recurrente aparición en sitios cercanos al área de estudio, el objetivo es analizar las estrategias de producción y utilización de esta tecnología en Cueva Maripe. Por otro lado, se evalúa si existen variaciones en su producción y si estas podrían ser consecuencia de la búsqueda de diseños específicos para un uso determinado.

\section{Sistema de Producción de Hojas}

El sistema de producción de hojas parte de una concepción volumétrica específica del núcleo debido a que el mismo debe tener una adecuada estructura desde el inicio de la cadena de producción, capaz de permitir el control de la longitud de los lascados y su recurrente extracción secuencial. Los núcleos prismáticos, en particular, permiten un control de las dimensiones de los lascados y, en algunos casos, los productos resultantes presentan un grado considerable de estandarización (Clark 1987). Esta uniformidad podría ser considerada como una ventaja en la manufactura de piezas confeccionadas para instrumentos compuestos; asimismo permite generar una mayor "vida útil" de los artefactos en función de la posibilidad de efectuar sucesivas reactivaciones (Böeda 1995). En este sentido, las hojas han sido definidas como lascas especializadas removidas intencionalmente de un núcleo preparado, dos veces más largas que anchas, exhiben por lo menos dos aristas que indican negativos de extracciones anteriores paralelas o subparalelas en la cara dorsal, presentan por lo general lados paralelos y sección triangular o trapezoidal (sensu Collins 2002:191, ver además Aschero 1975). Se diferencian de las láminas debido a que la producción de hojas presenta intencionalidad de obtener una determinada forma de artefacto a partir de núcleos preparados para tales fines (Collins 2002). Otras investigaciones mostraron interesantes resultados en el análisis del uso de hojas. Así, en el sitio Murphy, en Ohio, Yerkes (1990) registró que la mayoría de estas habrían sido utilizadas en una amplia variedad de tareas al igual que las lascas, y por lo tanto, tendrían poca especialización funcional. Los estudios realizados por Odell (1994) en el sector bajo del valle del río Illinois, Woodland medio, concluyeron que en contextos habitacionales las hojas habrían sido empleadas para diferentes tareas, tales como el procesamiento de presas y mantenimiento de instrumentos; mientras que en contextos mortuorios eran piezas numéricamente significativas y principalmente utilizadas para el raspado sobre materiales blandos. Estos resultados concuerdan en que las hojas sin retoques habrían sido multifuncionales y, por lo tanto, registran poca especialización funcional. Sin embargo, concluye en que el conocimiento del contexto del cual forma parte esta tecnología de hojas es fundamental para comprender su presencia y desaparición (Odell 1994).

Por otro lado en Sudamérica, a pesar de varios estudios referidos al desarrollo de esta tecnología (Hermo y Magnin 2012; Lourdeau et al. 2014; Suárez 2011), todavía no han proliferado análisis específicos relacionados con su funcionalidad.

A nivel local, los estudios referidos a la utilización de este tipo de tecnología corresponden exclusivamente a materiales recuperados en los niveles casapedrenses de Los Toldos (Cueva 2, 3 y 13), lo que permitió identificar el desarrollo de actividades relacionadas con las diferentes etapas del 
tratamiento de cueros y al procesamiento de presas (Paunero y Castro 2001). De la misma manera, en la Cueva 1 del sitio Cerro Tres Tetas (CTT) -Unidad 4(5.220 \pm 70 años a.p.) se registró un incremento en la estandarización del instrumental lítico, con un mayor énfasis en la producción de formas predeterminadas como hojas y/o láminas. Los estudios funcionales referidos a estos materiales evidenciaron áreas de procesamiento de cueros y preparación de huesos en las proximidades de los fogones localizados hacia el exterior de la cueva (Paunero et al. 2007). A partir de estos antecedentes y de acuerdo a los objetivos propuestos con anterioridad, el siguiente trabajo propone complementar los conocimientos acerca de esta tecnología en contextos habitacionales de Patagonia tomando el caso de Cueva Maripe.

\section{Descripción del Sitio}

Cueva Maripe se localiza en el curso medio del mallín La Primavera (Figura 1). Corresponde a una cueva de dimensiones considerables ( $24 \mathrm{~m}$ de boca y $26 \mathrm{~m}$ de profundidad), dividida internamente en dos Cámaras, norte $(\mathrm{CN})$ y sur (CS), con características microambientales particulares en base a la superficie de abrigo, exposición solar y humedad (Miotti et al. 2014).

Los estudios previos han permitido profundizar las hipótesis acerca de un uso diferencial del interior de la cueva, y evaluar los agentes que intervinieron en el estado de preservación de los materiales recuperados (Lynch et al. 2015; Miotti et al. 2014 y bibliografía allí citada).

La secuencia cultural del sitio está conformada por tres componentes ocupacionales. El primero de ellos (Componente 1) incluye conjuntos datados en la transición Pleistoceno-Holoceno y el Holoceno Temprano; el Componente 2 está representado por ocupaciones del Holoceno Medio y el Componente 3 presenta ocupaciones que van desde fines del Holoceno Medio al Holoceno Tardío (Hermo y Lynch 2015; Lynch 2016; Miotti et al. 2014).

En este trabajo se analizarán los conjuntos líticos del Componente 2, es decir la capa 4 de CN y la Unidad Analítica 2 (UA2) de CS. Las ocupaciones de estas unidades se ubican entre $5.376 \pm 45$ años a.p. y $3.210 \pm 60$ años a.p. en $\mathrm{CN}$; y entre $7.703 \pm 47$ años a.p. y $4.113 \pm 39$ años a.p. en CS (Miotti et al. 2014). Las tecnologías líticas representadas muestran diferencias notables con las ocupaciones anteriores debido al incremento en la producción de hojas, la aparición de tres fragmentos líticos de boleadoras y al aumento en el registro de materias primas no locales como la obsidiana (Hermo y Lynch 2015; Hermo y Magnin 2012; Lynch 2016).

\section{Muestra Observada y Metodología Aplicada}

En investigaciones previas se definió un total de 3.220 artefactos líticos recuperados en las excavaciones de Cueva Maripe. De este total en la capa 4 de $\mathrm{CN}$ se identificaron 109 hojas no retocadas, 20 artefactos formatizados elaborados sobre hojas (láminas retocadas, raspadores y artefactos con formatización sumaria) y tres núcleos con evidencia extractiva de hojas (Hermo y Lynch 2015; Hermo y Magnin 2012). Mientras que en la Unidad Analítica 2 (UA2) de CS, se reconocieron 355 hojas no retocadas, 63 artefactos formatizados cuyas formas base son hojas (artefactos con formatización sumaria, espolones, láminas retocadas y raspadores) y dos núcleos.

El estudio incluyó análisis tecnomorfológico y funcional de base microscópica. El conjunto estudiado fue agrupado en clases artefactuales (Aschero 1975, 1983), como núcleos, artefactos formatizados (AF) y no formatizados (ANF). Para el análisis de cada categoría se siguieron los criterios tecnomorfológicos y atributos dimensionales de distintos investigadores (Aschero 1975, 1983; Aschero y Hocsman 2004; Hermo 2008), teniendo en cuenta algunas variables descriptivas como: materia prima, tamaños y módulos, grupos tipológicos (para AF), morfología (en los núcleos) y características principales de los filos.

El análisis funcional se realizó en 72 piezas sobre las que se contabilizaron 147 filos, de los cuales 46 corresponden a AF elaborados sobre hojas que presentaron 109 filos y $26 \mathrm{ANF}$ (38 filos). Cabe aclarar que en el conjunto de ANF fueron consideradas las piezas con un tamaño mediano grande (sensu Aschero 1975, 1983) o mayor y con un filo potencialmente utilizable mayor a $30 \mathrm{~mm}$ (Lynch 2016).

Como se mencionó anteriormente, para la identificación de los rastros de uso se aplicó el análisis funcional de base microscópica (MansurFranchomme 1986-1990; Semenov 1976), herramienta de contrastación entre el diseño y la función de diferentes tecnologías líticas. El estudio se llevó a cabo a partir de la observación de los 

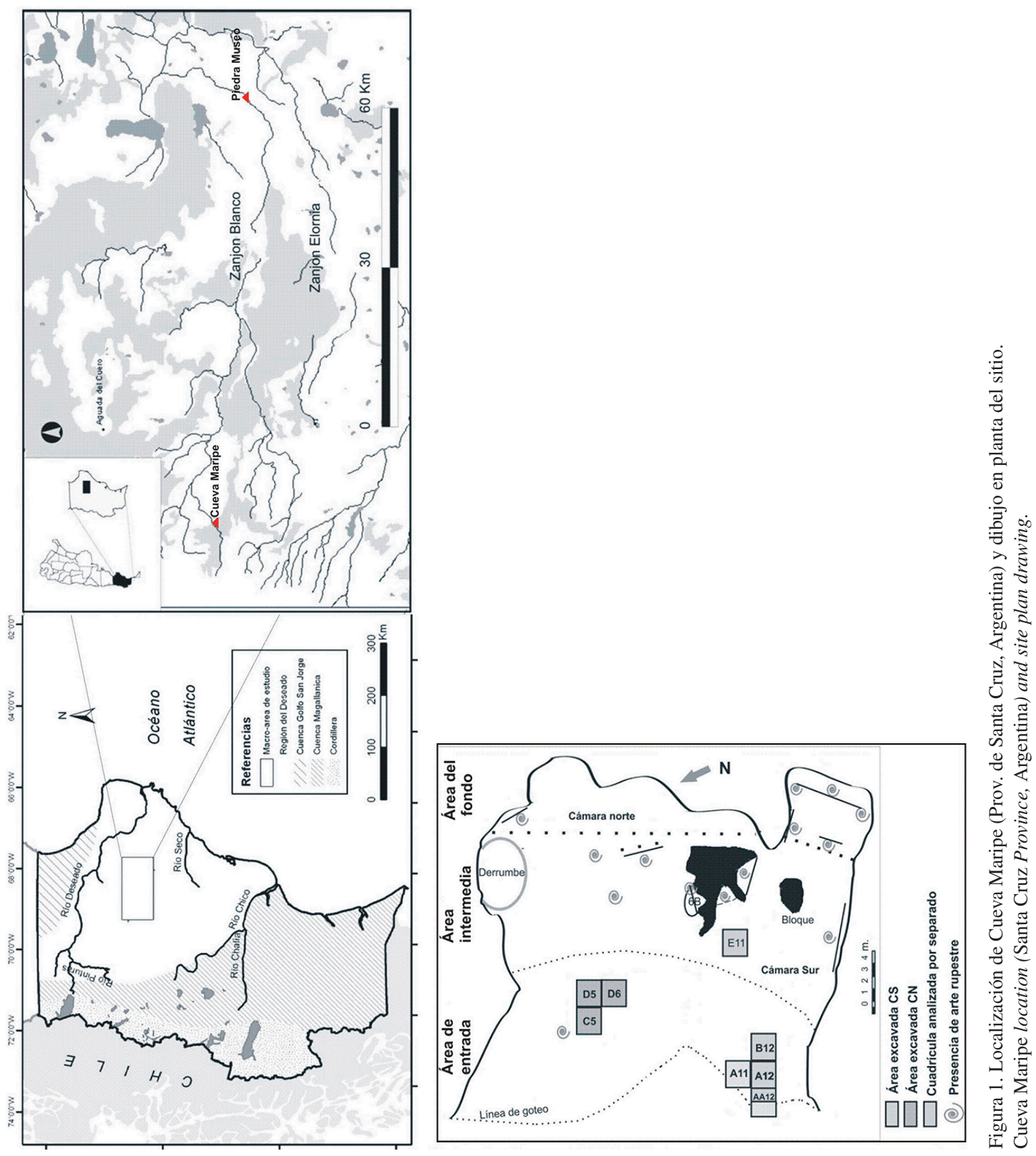
filos bajo un microscopio metalográfico Nikon Epiphoto 200 con aumentos de 50X a 500X y una lupa binocular Nikon SMZ 800, con aumentos de $10 \mathrm{X}$ a $63 \mathrm{X}$.

Con la finalidad de analizar tendencias y variaciones en la muestra estudiada se realizaron, a su vez, distintas pruebas estadísticas entre la longitud y ángulo del filo trabajado en relación al tipo de material utilizado y a la cinemática empleada. En este sentido, se utilizó la prueba U de Mann-Whitney para variables cuantitativas, mientras que para variables cualitativas se usaron pruebas no paramétricas mediante el Chi cuadrado de Pearson (Shennan 1992).

\section{Resultados}

\section{Análisis tecnomorfológico y funcional en la capa 4 de Cámara Norte}

Las materias primas identificadas en el conjunto corresponden a rocas de buena a muy buena calidad para la talla y de procedencia inmediatamente disponible y local (sensu Bayón y Flegenheimer 2004), carácter que se daría en toda la secuencia del sitio a excepción del caso de la obsidiana, procedente de las fuentes de Pampa del Asador y Cerro Bayo (ca. $120 \mathrm{~km}$ de distancia) (Hermo 2008; Magnin 2011; Stern 1999). En el conjunto analizado se registraron tres núcleos con evidencia de técnicas extractivas de hojas que presentan entre 10 a 11 extracciones cada uno. En cuanto a las materias primas, las mismas corresponden a las variedades locales, como la ignimbrita silicificada (variedad ISG1) y calcedonia (variedad CG1) (Hermo y Lynch 2015). Los ejemplares fueron clasificados como piramidales $(\mathrm{n}=2$; regular e irregular) y una pieza bifacial. La morfología de los dos primeros casos sugiere cierta estandarización en sus extracciones. Mientras que, el único núcleo de ISG1, del cual remonta una hoja sobrepasada (Figura 2A), presentó mayor cantidad de negativos de lascado y volumen que los demás ejemplares. En un trabajo previo dedicado al análisis de los núcleos de Cueva Maripe (Hermo y Lynch 2015), interpretamos que en el sitio se encuentran representadas estrategias de aprovisionamiento de lugar (sensu Kuhn 1995) de las que forma parte este núcleo.

En cuanto a los productos de talla (ANF), la muestra estuvo conformada por 16 hojas con 20 filos identificados, los cuales fueron observados en su totalidad bajo microscopía óptica. Las hojas de arista simple fueron las más representadas $(\mathrm{n}=10$, $62 \%)$ y en menor proporción de arista doble $(n=6$, $38 \%$ ) (Figura 2B). Según la clasificación empleada (Aschero 1975, 1983), el tamaño de las piezas es grande a mediano grande y presentan módulos principalmente laminares normales. La mitad de los ejemplares se encontraban fracturados, sin talón $(\mathrm{n}=10,50 \%)$ y en su mayoría presentaron un único filo potencialmente utilizable. Asimismo, algunas de las hojas recuperadas presentan talones con resto de corteza, natural cortical $(\mathrm{n}=2,10 \%)$ y liso natural $(n=5,25 \%)$. El porcentaje de hojas con corteza es bajo, es decir que en su mayoría se trata de elementos internos, a excepción de un único caso que registra reserva cortical superior al $50 \%$ de su superficie.

Las materias primas registradas en $\mathrm{CN}$ incluyen altos porcentajes de ignimbritas silicificadas variedad ISG1 ( $\mathrm{n}=8,50 \%)$, rocas silíceas de la variedad RSG2 $(\mathrm{n}=4,25 \%)$ y proporciones menores de xilópalo $(\mathrm{n}=2$, $13 \%)$, calcedonias y rocas silíceas de la variedad RSG1 ( $n=1,6 \%$ en cada caso).

El análisis funcional realizado sobre estos materiales permitió observar un porcentaje considerable de piezas con rastros de uso $(n=11$, $55 \%$ ) y le siguen en iguales proporciones de piezas no determinadas $(\mathrm{n}=3,15 \%)$ y no determinadas por alteración (abrasión sedimentaria y termoalteración -daño térmico-) $(\mathrm{n}=3,15 \%)$ y sin uso $(\mathrm{n}=3,15 \%$ cada uno) (Tabla 1).

En cuanto a las sustancias trabajadas por los filos observados, se reconocieron evidencias de acciones de corte $(n=5)$ y de raspado $(n=1)$ sobre material duro indiferenciado (55\%), tareas de corte sobre hueso $(n=3)$ y material no diferenciable $(n=2)$ (Figura 2C-D).

Las piezas que trabajaron sobre estos materiales presentaron una longitud promedio de $51,5 \mathrm{~mm}$ de largo, 22,7 de ancho y 6,8 de espesor. Respecto a las características principales de los filos utilizados a partir de movimientos longitudinales, se reconocieron principalmente filos de morfología rectilínea, ángulos agudos menores a $40^{\circ}$ y una longitud promedio de aproximadamente $44 \mathrm{~mm}$.

Por otro lado, los artefactos formatizados elaborados sobre hojas fueron 18 , en los que se identificaron 44 filos. La mayoría de las piezas se encontraban enteras $(n=8,42 \%) y$, al igual que en los ANF, los tamaños se distribuyen entre mediano-grandes y grandes (37\%), mientras que 

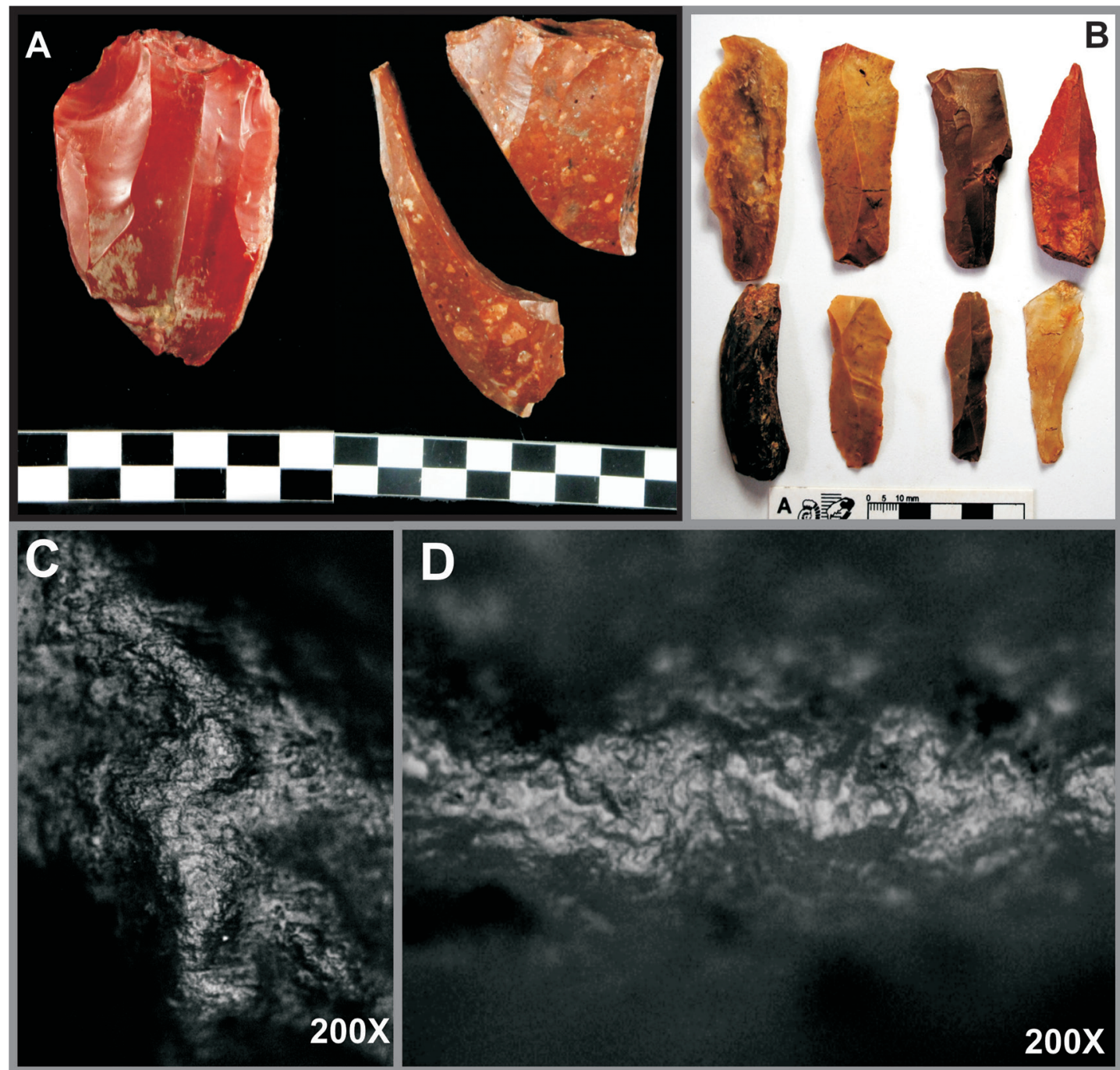

Figura 2. Materiales recuperados de la capa 4 en cámara norte. (A) Núcleos con extracciones de hojas. (B) Conjunto de hojas con filos naturales. (C) Trabajo sobre material duro animal a partir de acciones de corte y raspado. (D) Raspado sobre material duro vegetal. Materials recovered at layer 4 of north chamber. (A) Blade cores. (B) Unretouched blades. (C) Microtraces on tools used to work bone (cutting and scraping). (D) Traces of scraping on hard plant material.

el módulo de longitud/anchura está mayormente representado por piezas laminares normales. Respecto a la variabilidad de las materias primas utilizadas, se identificó el uso de calcedonias (variedad CG1 $\mathrm{n}=5,28 \%$ ), seguido de ignimbritas variedad ISG1 y variedad RSG2 de rocas silíceas ( $\mathrm{n}=4,22 \%$ cada uno), variedad de rocas silíceas RSG1 $(11 \%)$ y proporciones menores de ópalo (PG1, 6\%), xilópalo $(6 \%)$ y obsidiana $(5 \%)$.

Dentro de los grupos tipológicos se reconoció un mayor porcentaje de raspadores $(\mathrm{n}=12,57 \%)$, le siguen las láminas retocadas $(\mathrm{n}=5,24 \%)$ y filos no diferenciados y naturales con rastros complementarios ( $n=2,9 \%$ respectivamente) (Tabla 2). En relación con la cantidad de filos, se observaron principalmente piezas con filos múltiples $(n=10,53 \%)$, dobles $(n=5$, $26 \%)$ y simples $(n=4,21 \%)$. El mayor porcentaje de AF con filos múltiples está confeccionado sobre RSG2. Respecto a las sustancias trabajadas, se registró que el uso del filo principal (frontal en los raspadores) coincidía con el de sus filos complementarios.

$\mathrm{El}$ análisis funcional realizado en los $\mathrm{AF}$ confeccionados sobre hojas arrojó altos porcentajes 
Tabla 1. Integridad artefactual de los materiales elaborados sobre hojas del Componente 2 en Cueva Maripe. Artifactual integrity in assemblage 2 at Cueva Maripe site.

\begin{tabular}{|c|c|c|c|c|c|c|c|c|}
\hline \multirow[b]{2}{*}{$\begin{array}{l}\text { Integridad } \\
\text { Artefactual }\end{array}$} & \multicolumn{5}{|c|}{ Cámara Norte (Capa 4) } & \multicolumn{3}{|c|}{ Cámara Sur (UA 2) } \\
\hline & $\begin{array}{c}\text { Artefactos } \\
\text { formatizados } \\
\quad(n=19)\end{array}$ & $\%$ & $\begin{array}{l}\text { Artefactos no } \\
\text { formatizados } \\
\quad(n=16)\end{array}$ & $\%$ & $\begin{array}{c}\text { Artefactos } \\
\text { formatizado } \\
(n=27)\end{array}$ & $\%$ & $\begin{array}{c}\text { Artefactos no } \\
\text { formatizados } \\
\quad(n=11)\end{array}$ & $\%$ \\
\hline Con uso & 18 & 41 & 11 & 55 & 16 & 25 & 7 & 39 \\
\hline No determinado & 14 & 32 & 3 & 15 & 25 & 38 & 4 & 22 \\
\hline $\begin{array}{c}\text { No determinado por } \\
\text { alteración }\end{array}$ & 11 & 25 & 3 & 15 & 24 & 37 & 6 & 33 \\
\hline Sin uso & 1 & 2 & 3 & 15 & - & - & 1 & 6 \\
\hline Total de filos & 44 & 100 & 20 & 100 & 65 & 100 & 18 & 100 \\
\hline
\end{tabular}

Tabla 2. Artefactos formatizados elaborados sobre hojas del Componente 2 de Cueva Maripe (Aschero 1975:54). Blades tools in assemblage 2 at Cueva Maripe (Aschero 1975:54).

\begin{tabular}{lcccr}
\hline \multicolumn{1}{c}{ Grupos tipológicos } & Capa $4(\mathrm{CN})$ & $\%$ & $\begin{array}{c}\text { Unidad analítica 2 } \\
(\mathrm{CS})\end{array}$ & $\%$ \\
\hline Con formatización sumaria & 2 & 9 & 1 & 3 \\
Espolones & - & - & 2 & 7 \\
Filo no diferenciable & 2 & 10 & - & - \\
Lámina retocada & 5 & 24 & 10 & 40 \\
Raspador & 10 & 57 & 14 & 50 \\
Total & 19 & 100 & 27 & 100 \\
\hline
\end{tabular}

de filos con rastros de uso sobre diferentes materiales $(\mathrm{n}=18,41 \%)$, (Figura 3 ) y un porcentaje considerable de no determinados por alteración $(\mathrm{n}=11,25 \%)$ (Tabla 1). Las piezas alteradas presentaron un grado severo (Lynch 2016), imposibilitando la identificación funcional. Las alteraciones más frecuentes fueron abrasión sedimentaria $(70 \%) \mathrm{y}$, en proporciones menores, termoalteración (20\%) y lustre (10\%).

Dentro del grupo de láminas retocadas se registraron filos que trabajaron sobre material duro indiferenciado a partir de acciones de corte $(n=3)$ y de raspado $(n=2)$. Sin embargo, también fueron empleadas en otras actividades, como el trabajo sobre material duro de origen vegetal o animal (hueso) en acciones de corte ( $\mathrm{n}=1$, respectivamente) (Figura 4).

El grupo de raspadores fue empleado sobre una mayor diversidad de materiales con diferentes durezas (blando, intermedio y duro); principalmente habrían intervenido en acciones de raspado sobre madera $(n=3) y$, en menor medida, en acciones de corte sobre este mismo material $(n=1)$ y sobre sustancias no determinadas $(n=2)$. Los trabajos sobre cuero $(n=1)$ y material duro indiferenciado $(n=4)$ también fueron realizados mediante raspadores a partir de sus filos frontales.

Las pruebas estadísticas realizadas en base a la longitud y ángulo de los filos utilizados sobre material duro indiferenciado y animal, a partir de distintas cinemáticas, arrojaron diferencias significativas entre los ángulos de los filos empleados longitudinal y transversalmente (M-W: $\mathrm{U}=14, \mathrm{p}=0,01)$. Sin embargo, estas diferencias no fueron registradas en relación con la longitud de los filos utilizados.

En este sentido, el ángulo elegido para el trabajo sobre materiales duros se habría priorizado respecto a la longitud de los filos, y por lo tanto habría tenido una mayor incidencia en el desarrollo de las distintas actividades y cinemáticas ejercidas. Por otro lado, también se observaron diferencias significativas en el espesor de las piezas trabajadas mediante distintas cinemáticas $(\mathrm{U}=5,50, \mathrm{p}=0,01)$ (Figura 5). Aquellas utilizadas longitudinalmente fueron significativamente menos espesas (promedio cercano a $6,1 \mathrm{~mm}$ ) que las empleadas en actividades de raspado $(9,8 \mathrm{~mm})$. Esta diferencia es interpretada 


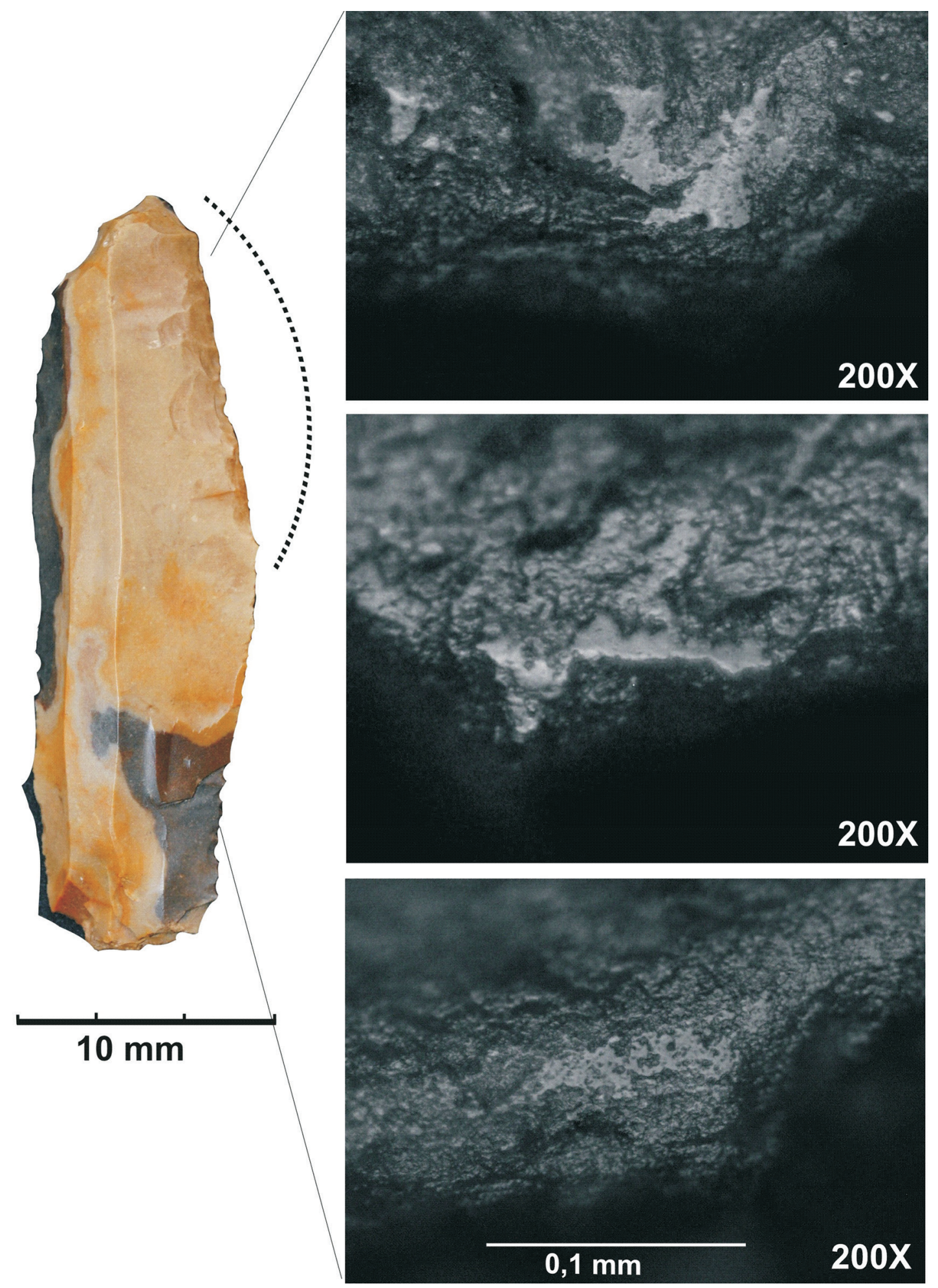

Figura 3. Artefacto formatizado elaborado sobre hoja (MA349), registra rastros de uso sobre material duro animal en acciones de corte. Blade tool (MA349) with micro traces of cutting on hard animal materials. 


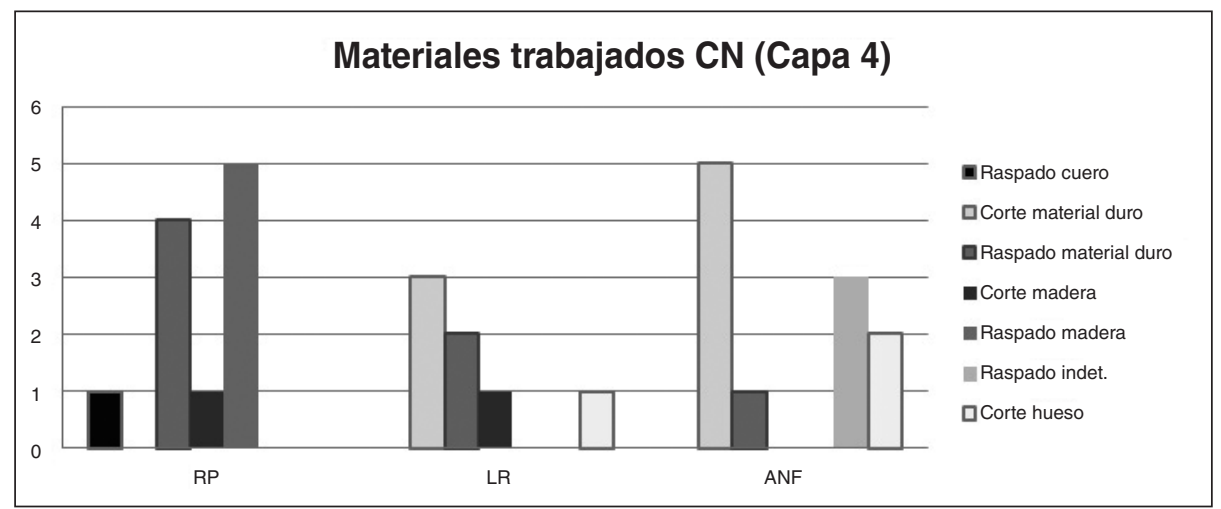

Figura 4. Materiales trabajados identificados en capa 4 de Cámara Norte. RP: raspadores. LR: láminas retocadas. ANF: artefactos no formatizados.

Worked materials identified at North Chamber (Layer 4). RP: end-scrapers. LR: retouched blades. ANF: unretouched blades.

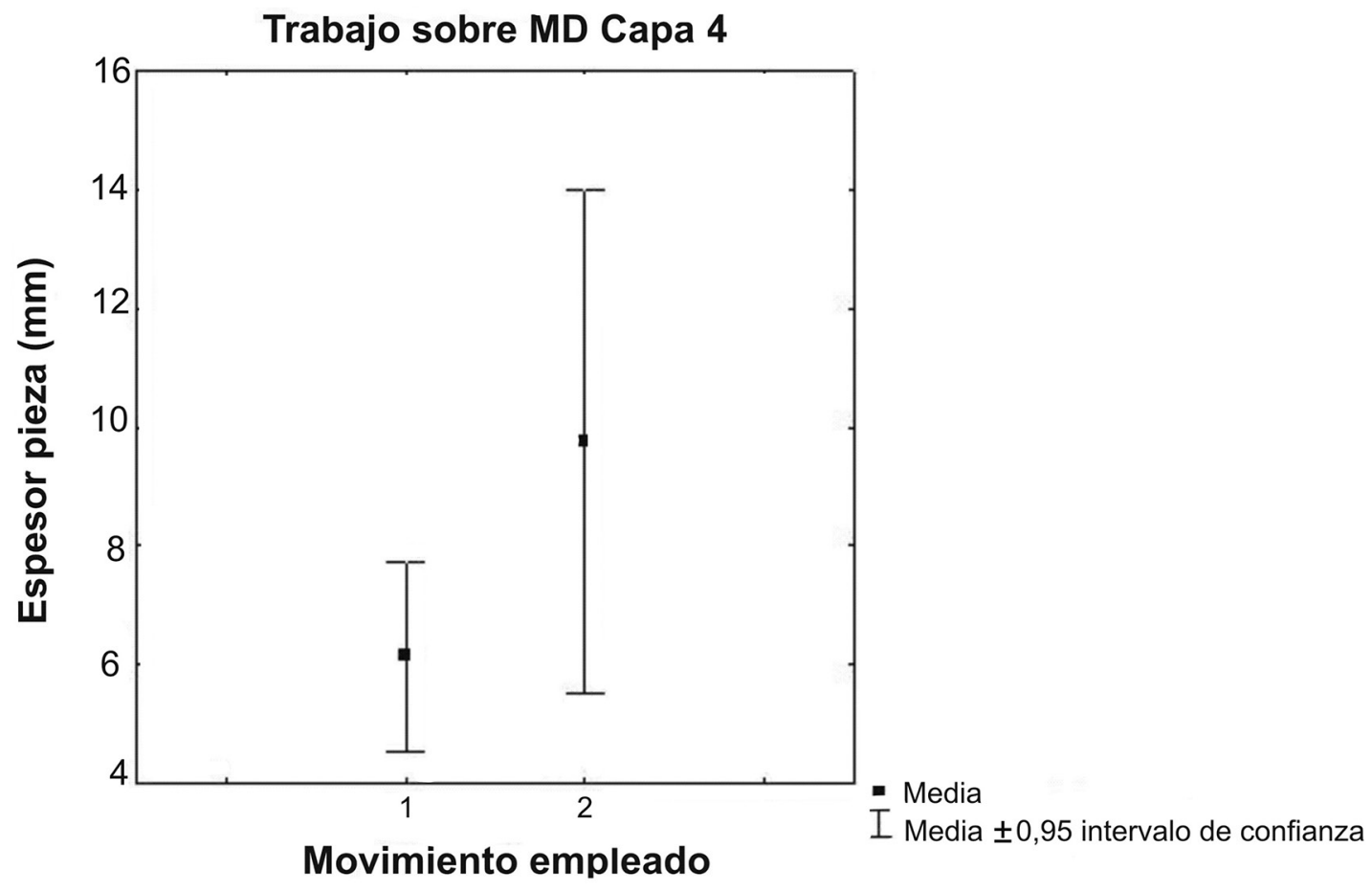

Figura 5. Diferencia significativa del espesor de las piezas trabajadas sobre material duro a partir de distintas cinemáticas en Capa 4. (1) Acciones longitudinales. (2) Acciones transversales.

Significant difference on thickness of artifacts worked on hard material with different kinematics at Layer 4. (1) Cutting motions. (2) Scraping motions. 
como resultado de un diseño artefactual que consideró la fuerza ejercida durante el empleo de la herramienta, ya que en actividades de raspado la resistencia de la pieza debe ser mayor en la porción medial, evitando así posibles fracturas (Álvarez et al. 2000).

\section{Análisis tecnomorfológico y funcional en la Unidad Analítica 2 Cámara Sur}

En la Cámara Sur se recuperaron dos núcleos, uno con extracciones de lascas y hojas y otro de hojas. Ambos casos corresponden a un ópalo (variedad PG1) de coloración negro-rojiza y presentan una cantidad mínima de 7 negativos de lascados. El núcleo de hojas presenta un menor volumen $\left(20.365,63 \mathrm{~mm}^{3}\right)$ respecto del de lascas y hojas $\left(21.049,71 \mathrm{~mm}^{3}\right)$.

El conjunto de ANF incluye 11 piezas y se contabilizaron 18 filos; en su mayoría los ejemplares se encuentran fracturados, sin talón $(n=5,46 \%)$. El tamaño de las piezas es principalmente grande, de módulo laminar normal y mediano alargado. Se identificó una mayor proporción de hojas de arista simple $(n=7,64 \%)$. En esta unidad se observó asimismo variabilidad en los tipos de talón, donde el facetado fue el más representado $(n=2,28 \%)$, con proporciones menores de lisos, diedros y puntiformes $(\mathrm{n}=1,9 \%$, respectivamente). En el conjunto se registró un mayor número de piezas con corteza $(n=7,64 \%)$, a diferencia de la $\mathrm{CN}$ donde un solo caso registró más del 50\% de reserva cortical en su cara dorsal.

Por otra parte, al igual que en toda la secuencia de Cueva Maripe, la variedad ignimbrita silicificada grupo 1 (ISG1) fue la materia prima mayormente utilizada en el Componente 2 de la CS ( $n=3,28 \%)$, seguida por proporciones menores por xilópalo, variedades de rocas silíceas (RSG2, RSG3) y calcedonia variedad CG1.

El análisis funcional arrojó un número considerable de piezas con rastros de uso $(n=7,39 \%)$ $\mathrm{y}$ porcentajes elevados de piezas no determinadas debido a la presencia de alteración $(n=6,33 \%)$ (Tabla 1). Las alteraciones registradas fueron la abrasión sedimentaria y otras ocasionadas por la exposición directa al fuego. En dichos casos, el análisis funcional no pudo ser llevado a cabo debido al registro de un grado severo de alteración. En las piezas con rastros reconocibles se identificó el uso sobre hueso $(n=2)$ y material duro indiferenciado $(n=4)$, trabajaron en su mayoría longitudinalmente, a excepción de un solo caso en el que se emplearon movimientos transversales. El micropulido de cuero fue identificado en una pieza que fue utilizada en acciones de corte mediante movimientos longitudinales (Figura 6).

Las hojas utilizadas sobre materiales duros presentaron una longitud cercana a $51,1 \mathrm{~mm}$, ancho de $18,9 \mathrm{~mm}$ y espesor de $6,4 \mathrm{~mm}$; dimensiones similares a las registradas en la CN. Los filos presentaron una morfología principalmente rectilínea o convexa atenuada, de sección longitudinal rectilínea, con ángulos entre los $25^{\circ}$ y $50^{\circ}$ y longitud promedio de 40,5 mm. A diferencia de estos, la hoja empleada sobre material blando (cuero) presentó un filo más recto $\left(\right.$ de $60^{\circ}$ ) y con una longitud de $44 \mathrm{~mm}$ (Tabla 3 ).

En cuanto a los AF elaborados sobre hojas, fueron registradas 27 piezas. Se identificaron y analizaron 65 filos. En su mayoría los ejemplares se encontraban fracturados, sin talón $(n=8,34 \%)$. Dentro de los grupos tipológicos identificados, los raspadores $(\mathrm{n}=14,50 \%)$ son los más representados, sin embargo también pudieron ser recuperadas láminas retocadas $(n=10,36 \%)$, espolones $(n=2$, $7 \%)$ y artefactos con formatización sumaria $(\mathrm{n}=1$, 4\%) (Tabla 2).

Con respecto a las dimensiones relativas de las piezas, las mismas fueron principalmente medianograndes y grandes, con módulos de longitud/anchura laminar normal y mediano alargado. La materia prima más representada es la ignimbrita silicificada variedad ISG1 $(n=10,37 \%)$, en menor medida se registran calcedonia CG1 $(\mathrm{n}=4,15 \%)$, ópalo PG1 y xilópalo ( $\mathrm{n}=3,11 \%$ cada una), proporciones menores de rocas silíceas RSG1 $(n=2,8 \%)$ y RSG3 $(n=2,7 \%)$ y 3 casos $(11 \%)$ que no pudieron ser identificadas.

La mayoría de los ejemplares presentan filos complementarios, los cuales en el caso de los raspadores correspondían principalmente a filos naturales $(52 \%)$ y, en menor medida, de raspadores y raederas (15\% y $7 \%$, respectivamente).

El análisis funcional efectuado sobre los materiales arrojó un bajo número de filos con rastros de uso identificables $(\mathrm{n}=16,25 \%)$, no determinados $(\mathrm{n}=25,38 \%)$ y no determinados por alteración $(\mathrm{n}=24$, $37 \%$ ). Las alteraciones registradas presentaron un grado severo, lo que dificultó la identificación funcional. $\mathrm{Al}$ igual que en la $\mathrm{CN}$, se registró abrasión sedimentaria y termoalteración (daño térmico); sin embargo, en este caso, también se reconoció la depositación de carbonatos sobre las superficies de las piezas, lo que podría estar relacionado con una mayor humedad registrada en este sector de la cueva (Lynch et al. 2015). 


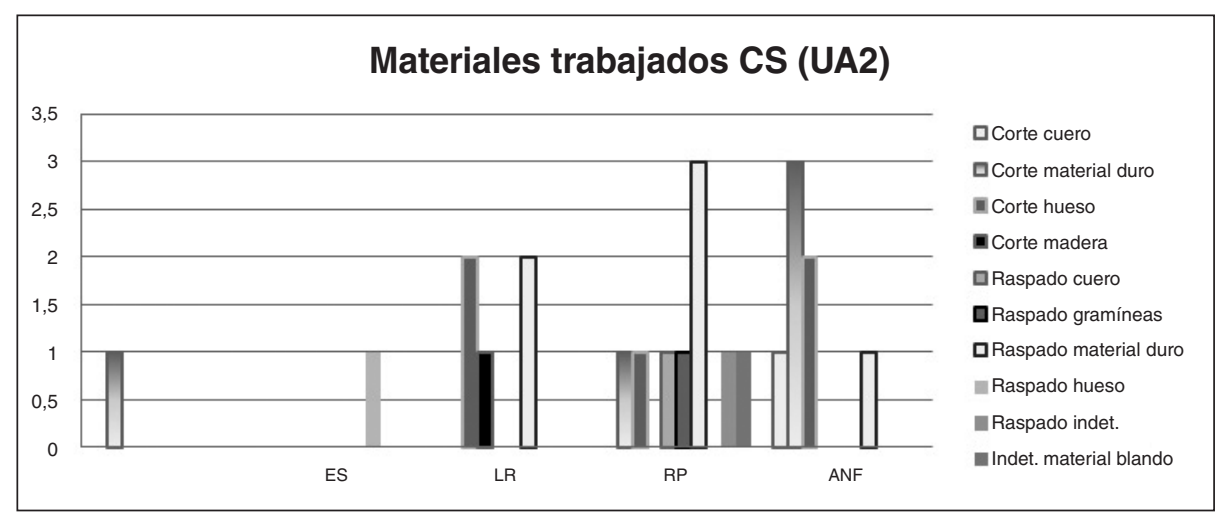

Figura 6. Inferencia funcional de los materiales recuperados en cámara sur. AFS: artefactos con formatización sumaria. ES: espolones. LR: láminas retocadas. RP: raspadores. ANF: artefactos no formatizados.

Microwear analysis results of materials recovered at south chamber. AFS: scantily retouched flakes. ES: spurs. LR: retouched blades. RP: end-scrapers. ANF: unretouched blades.

Tabla 3. Características generales y datos métricos de hojas no retocadas con rastros de uso del Componente 2 de Cueva Maripe. General features and metric data of used unretouched blades in assemblage 2 at Cueva Maripe.

\begin{tabular}{|c|c|c|c|c|c|c|c|}
\hline $\begin{array}{c}\mathrm{N}^{\circ} \text { Pieza } \\
\text { ANF }\end{array}$ & Estado & Materia prima & $\begin{array}{l}\text { Longitud } \\
\text { (mm) }\end{array}$ & $\begin{array}{c}\text { Ancho } \\
(\mathrm{mm})\end{array}$ & $\begin{array}{c}\text { Espesor } \\
(\mathrm{mm})\end{array}$ & Tipo de hoja & Uso \\
\hline \multicolumn{8}{|c|}{ Cámara Norte (Capa 4) } \\
\hline MAC5241 & Fracturada & Ignimbrita silicificada & 41,15 & 26 & 5,7 & De arista simple & Raspado no determinado \\
\hline MAD5253 & Fracturada & Roca silícea G1 & 41,95 & 37,2 & 6,3 & De arista doble & Corte material duro \\
\hline MAD5341 & Fracturada & Xilópalo & 47,35 & 15 & 4,8 & De arista simple & Corte material duro \\
\hline MAD5341 & Fracturada & Xilópalo & 47,35 & 15 & 4,8 & De arista simple & Corte material duro animal \\
\hline MAD6312 & Fracturada & Roca silícea G2 & 79 & 34,5 & 10 & De arista doble & Corte material duro \\
\hline MAD6177j & Entera & Xilópalo & 63,2 & 20,5 & 14,4 & De arista simple & Raspado no determinado \\
\hline MAD6215 & Fracturada & Roca silícea G2 & 43 & 10 & 2 & De arista doble & Corte hueso \\
\hline MAD6289 & Fracturada & Ignimbrita silicificada & 48,6 & 27,9 & 15,5 & De arista doble & Raspado material duro \\
\hline MAD636 & Entera & Roca silícea G2 & 54,9 & 22,5 & 4,5 & De arista doble & Corte hueso \\
\hline MAD639 & Fracturada & Roca silícea G2 & 50,9 & 19,9 & 6,9 & De arista simple & Corte material duro \\
\hline MAD6215 & Fracturada & Ignimbrita silicificada & 46 & 14,2 & 4,5 & De arista simple & Corte material duro \\
\hline \multicolumn{8}{|c|}{ Cámara Sur (Unidad analítica 2) } \\
\hline MAB12148 & Fracturada & Roca silícea G3 & 48,3 & 13 & 6,65 & $\mathrm{C} /$ dorso natural & Corte hueso \\
\hline MAB12148 & Fracturada & Roca silícea G3 & 48,3 & 13 & 6,65 & C/dorso natural & Corte cuero \\
\hline MAA12328 & Fracturada & Ignimbrita silicificada & 47,5 & 19,7 & 6,1 & De arista doble & Corte material duro \\
\hline MAA12367 & Fracturada & Calcedonia & 48,8 & 12,6 & 4,2 & De arista simple & Corte material duro \\
\hline MAB12392b & Fracturada & Xilópalo & 58 & 21 & 4,2 & De arista doble & Raspado material duro \\
\hline MAB12344 & Entera & Xilópalo & 57 & 28 & 11 & De arista doble & Corte material duro \\
\hline MAB12344 & Entera & Xilópalo & 57 & 28 & 11 & De arista doble & Corte hueso \\
\hline
\end{tabular}

En cuanto a los materiales trabajados por el grupo de raspadores, se identificó un uso principalmente sobre sustancias duras indiferenciadas y, en su mayoría, en acciones de raspado. Sin embargo, el trabajo sobre materiales blandos (cuero, material vegetal e indiferenciado) fue igualmente registrado en tres casos. El grupo de láminas retocadas fue utilizado exclusivamente sobre materiales duros, tanto de origen vegetal $(n=1)$ como animal $(n=2)$ y a partir de movimientos longitudinales o de corte. Mientras que en dos casos se reconoció únicamente la dureza relativa del material trabajado (duro) y su utilización en acciones de raspado (Figura 6). 
Las pruebas estadísticas realizadas en función del ángulo y la longitud de los filos utilizados mediante diferentes cinemáticas sobre material duro, resultaron significativas respecto a los ángulos empleados $(\mathrm{U}=10, \mathrm{p}=0,01)$, al igual que en $\mathrm{CN}$ (Figura 7). En el caso de la longitud esta diferencia no fue registrada $(U=19, p=0,10)$.

De acuerdo a esto, al igual que lo expresado anteriormente en la $\mathrm{CN}$, la elección de determinados ángulos en el empleo de tareas específicas habría tenido cierta incidencia en la producción del diseño general de estos instrumentos elaborados a partir de hojas. Asimismo, y en el caso particular de la CS, el ángulo de los filos empleados longitudinalmente (ca. $33^{\circ}$ ) sería significativamente más agudo que aquellos utilizados de manera transversal (ángulo promedio de $52^{\circ}$ ), lo que sugiere un mejor ángulo de penetración y eficacia sobre el material trabajado. Debido al bajo registro de filos utilizados sobre material blando animal y/o cuero, estas diferencias no pudieron ser registradas estadísticamente teniendo en consideración los ángulos de los filos.

\section{Discusión y Conclusiones}

La información generada a partir de los materiales líticos del Componente 2 de Cueva Maripe ha permitido indagar acerca de la secuencia de producción y uso de la tecnología de hojas desarrollada durante el Holoceno Medio (ca. 7.500 a 3.000 años a.p.).

Los núcleos de hojas recuperados corresponden a las variedades de ignimbrita silicificada (ISG1), calcedonia (CG1) y ópalo (PG1), al igual que las hojas registradas en el Componente 2 de Cueva Maripe. Sin embargo, en CN la mayoría de las hojas recuperadas no presentan corteza, a excepción de un único caso en donde dicho rasgo

\section{Trabajo sobre MD UA2 CS}

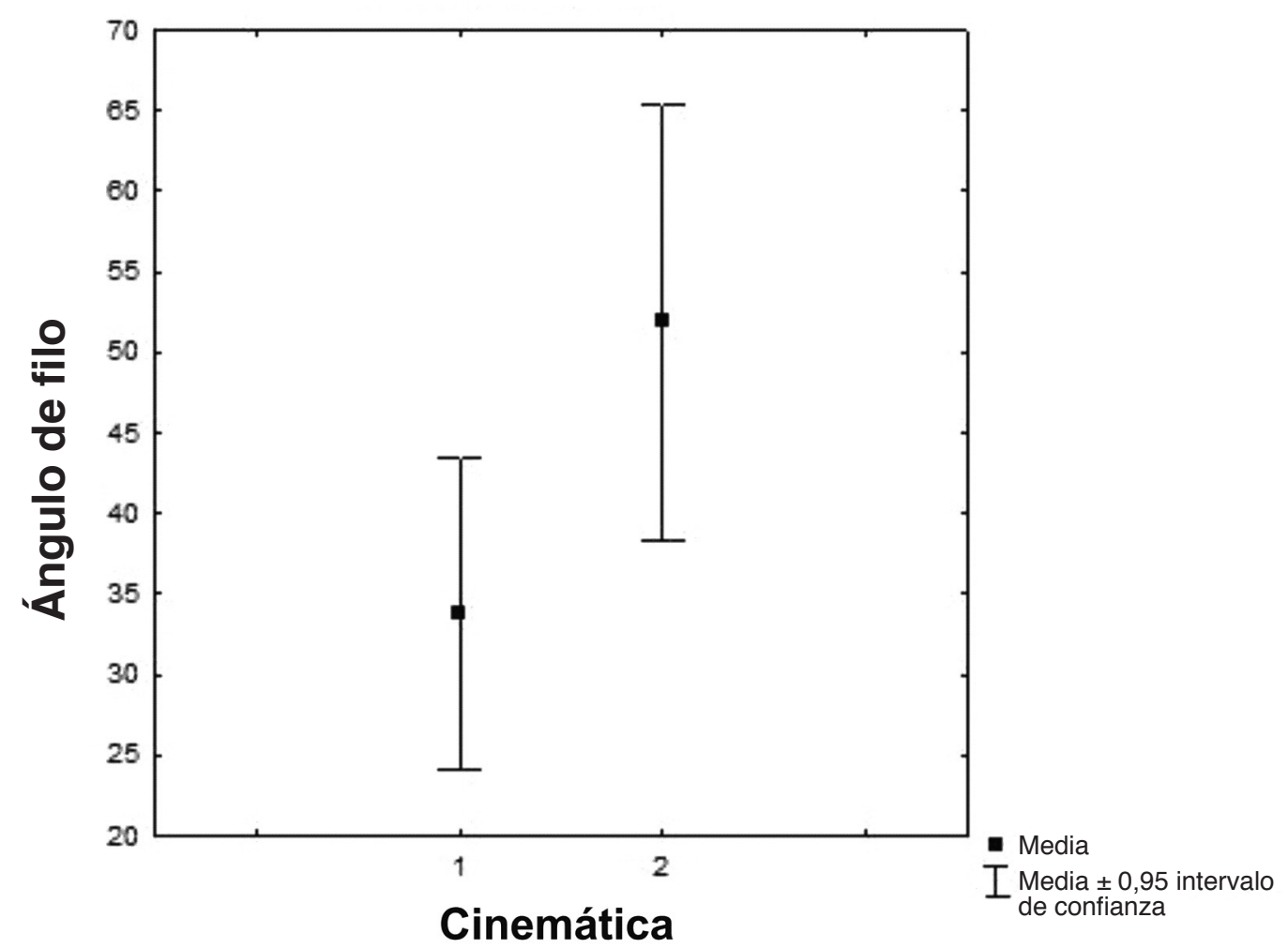

Figura 7. Diferencias significativas entre el ángulo del filo utilizado y las cinemáticas empleadas en el trabajo sobre material duro (MD) en la Unidad Analítica 2 (UA2). (1) Acciones longitudinales o de corte. (2) Acciones transversales o de raspado. Significant differences between in the edge angle and kinematics used on hard materials from Analytical Unit 2 (AU2). (1) Cutting motions. (2) Scraping motions. 
constituye más del 50\% de la pieza. Mientras que en CS las frecuencias de artefactos con corteza se incrementa. La presencia de núcleos con evidencias de extracciones laminares, sumado al registro de productos de talla con o sin corteza del mismo tipo de materia prima y a la variabilidad en la morfología de los talones (que incluye elementos corticales), sugieren que en Cueva Maripe se realizaron diferentes etapas de la producción de hojas. En este sentido, es importante remarcar que algunas de las materias primas obtenidas de fuentes primas no necesariamente mostrarían remanente de corteza en las lascas correspondientes a las primeras etapas de reducción (Hermo y Lynch 2015).

Cabe mencionar también, que habrían sido utilizadas otras variedades de rocas en su producción, silíceas de los grupos RSG1 y RSG2 y xilópalo, aunque en menores proporciones. Sin embargo, hasta el momento, no han sido recuperados núcleos tallados sobre estas rocas en el interior del sitio, por lo que interpretamos que las hojas habrían sido introducidas como elementos manufacturados, o bien que los núcleos en cuestión habrían sido transportados fuera del sitio en el marco de estrategias de aprovisionamiento individual (Hermo y Lynch 2015).

A su vez, llama la atención la alta proporción de hojas fracturadas registradas en ambos sectores de la cueva, lo que resulta un elemento disparador para realizar estudios más específicos acerca de su génesis (Flegenheimer y Weitzel 2007; Walker 1995). Estos altos índices podrían haber sido generados por factores post-depositacionales (pisoteo) o debido a cierta intencionalidad asociada con distintas estrategias tecnológicas; como la inserción en diferentes dispositivos de enmangues. En estudios anteriores, una muestra de raspadores asociados a ocupaciones del Holoceno Medio y analizados bajo microscopia óptica, registró micropulidos de material duro indiferenciado y residuos de coloración negra en sectores proximales de fracturas, lo que nos permitiría formular esta idea (Lynch y Hermo 2015).

A su vez, los resultados obtenidos del análisis funcional mostraron que la producción de hojas estuvo relacionada con el desarrollo de actividades de consumo (principalmente del guanaco, Miotti y Marchionni 2014) y con distintas etapas vinculadas al tratamiento de cueros, ya sea en la preparación de pieles o para generar tientos u otros enseres.

Los artefactos formatizados elaborados a partir de hojas incluyeron los grupos de raspadores, láminas retocadas, espolones y artefactos con formatización sumaria. Los resultados obtenidos del análisis realizado en los raspadores elaborados sobre hojas permitieron comprobar que únicamente en cuatro casos se identificó el trabajo mediante acciones de raspado y corte sobre materiales blandos (i.e. cuero y gramíneas); mientras que los demás fueron empleados en actividades de corte y raspado sobre material duro vegetal (Figura 2). Por lo tanto, estos raspadores habrían participado en actividades relacionadas con la extracción y tratamiento de pieles y cueros; mientras el trabajo sobre material duro vegetal sugiere que a su vez, habrían intervenido en el complejo tecnológico empleado para la manufactura de distintos dispositivos de enmangues, lo que habría facilitado la prehensión de diferentes instrumentos (Álvarez et al. 2000; Castro y Moreno 1994; Lynch y Hermo 2015; Lynch y Miotti 2016; Mansur y Lasa 2005).

En el caso de las láminas retocadas se evidencia un uso casi exclusivo sobre materiales duros (de origen animal) en acciones de corte, resaltando así la uniformidad de los movimientos empleados en función de los soportes utilizados. Creemos que estas piezas estarían relacionadas exclusivamente con actividades de procesamiento secundario de presas y a otras tareas, como la producción de artefactos sobre material óseo. Miotti y Marchionni (2014) han propuesto que

\section{...la significativa presencia de instrumentos confeccionados sobre metapodios, se debe a que estos huesos hayan sido transportados intencionalmente a los sitios, donde, se les podría haber extendido la vida útil transformándolos, luego del consumo de su alimento (médula), en instrumentos, como pueden ser los retocadores, punzones, etc... (Miotti y Marchionni 2014:126).}

Por otro lado, el análisis funcional de hojas con filos naturales arrojó baja cantidad de piezas con rastros de uso; sin embargo en algunos casos pudo identificarse el desarrollo de actividades de corte sobre materiales blandos (cuero) y duros (hueso). Estas bajas frecuencias podrían estar relacionadas al escaso tiempo de utilización de estos elementos en actividades de corte (procesamiento de animales), dificultando la inferencia funcional. Sin embargo, estos filos naturales habrían sido utilizados principalmente sobre materiales duros, con un promedio de longitud 
de $42 \mathrm{~mm}$, agudos y de morfología rectilínea. Estos caracteres les brindarían un mayor ángulo de penetración y eficacia durante su empleo en acciones longitudinales; al igual que mayor probabilidad de fractura, principalmente en la porción medial de la pieza, donde se habría ejercido una mayor fuerza. Las frecuencias elevadas de fracturas fueron mencionadas en párrafos anteriores y podrían deberse a este motivo, siendo aprovechadas para la transformación de estos elementos en otros capaces de ser utilizados mediante dispositivos de enmangue. Sin embargo, estas ideas prematuras deberán ser contrastadas en el futuro.

En este sentido, y a partir de los resultados obtenidos, se podría plantear que la producción de hojas en Cueva Maripe no estaría vinculada con la maximización de materias primas, dado que existen numerosas fuentes de aprovisionamiento lítico primario y secundario cercanas al sitio y con una amplia disponibilidad de variedades de rocas aptas para la talla (Franco et al. 2012; Hermo 2008; Hermo et al. 2015). Esta oferta natural de rocas se expresa en la variabilidad de materias primas líticas registradas en el Componente 2 de Cueva Maripe (Hermo y Lynch 2015); y por lo tanto, la producción de hojas implicaría una tecnología orientada a la obtención de diseños versátiles y/o mantenibles (Nelson 1991) con filos de características propicias (largo y rectilíneo) para su uso sobre diferentes materiales y durezas (i.e. cuero, hueso, madera, gramíneas).
En este sentido, coincidimos con las propuestas planteadas por Paunero et al. (2007) acerca de la producción de hojas en la meseta central de Santa Cruz, los cuales la caracterizan como un diseño de formas predeterminadas utilizadas principalmente en el consumo del guanaco y para la producción de otro tipo de tecnologías (i.e. dispositivos de enmangues) (Lynch 2016; Lynch y Hermo 2015). Cabe mencionar asimismo que la tecnología de hojas, sumada al registro de bolas de boleadoras, sería a su vez interpretada como parte de los cambios tecnológicos que se venían gestando a nivel regional en este sector de Patagonia (Aschero 1987; Cardich y Flegenheimer 1978; Orquera 1984-85). La alta frecuencia y variabilidad artefactual respondería a ocupaciones más recurrentes y de carácter residencial; rasgo igualmente observado en otros contextos del Holoceno Medio en la región (Aschero 1987; Civalero 1999; Durán 2004; Franco 2008; Paunero et al. 2007; Skarbun 2009).

Agradecimientos: A la Dra. Laura Miotti, al Laboratorio de Arqueología de Mesetas Patagónicas (FCNyM-UNLP) y a los evaluadores anónimos por las observaciones y comentarios realizados. Esta investigación ha sido subsidiada por CONICET (PIP-N207), UNLP (PI-N665 y PPID N010) y ANPCyT (PICT 0102).

\section{Referencias Citadas}

Álvarez, M., A.E. Lasa y M.E. Mansur 2000. La explotación de recursos naturales perecederos: análisis funcional de los raspadores de la costa norte del canal Beagle. Relaciones de la Sociedad Argentina de Antropología XXV:275-295.

Aschero, C.A. 1975. Ensayo para una clasificación morfológica de artefactos líticos aplicada a estudios tipológicos comparativos. Informe a CONICET. Buenos Aires. Manuscrito en posesión del autor.

Aschero, C.A. 1983. Ensayo para una clasificación morfológica de artefactos líticos. Apéndice A y B. Cátedra de Ergología y Tecnología. Universidad de Buenos Aires. Manuscrito en posesión del autor.

Aschero, C.A. 1987. Tradiciones culturales en la Patagonia Central -una perspectiva arqueológica-. En Primeras Jornadas de Arqueología de la Patagonia, pp. 17-32. Rawson, Chubut.

Aschero, C.A y S. Hocsman 2004. Revisando cuestiones tipológicas en torno a la clasificación de artefactos bifaciales. En Temas de Arqueología. Análisis Lítico, compilado por A. Acosta, D. Loponte y M. Ramos, pp. 7-26. Universidad Nacional de Luján, Buenos Aires.

Aschero, C., C. Bellelli y R. Goñi 1992-93. Avances en las investigaciones arqueológicas del Parque Nacional Perito
Moreno (provincia de Santa Cruz, Argentina). Cuadernos del INAPL 14:143-170.

Bayón, C. y N. Flegenheimer 2004. Cambio de planes a través del tiempo para el traslado de roca en la pampa bonaerense. Estudios Atacameños 28:59-70.

Boëda, E. 1995. Levallois: A volumetric construction, methods, a technique. En The Definition and Interpretation of Levallois Technology. World Archaeology, editado por L. Dibble y O. Bar-Yosef, pp. 41-68. Prehistory Press, Madison.

Cardich, A., L. Cardich y A. Hajduk 1973. Secuencia arqueológica y cronología radiocarbónica de la Cueva 3 de Los Toldos (Santa Cruz, Argentina). Relaciones de la Sociedad Argentina de Antropología VII:87-122.

Cardich, A. y N. Flegenheimer 1978. Descripción y tipología de las industrias más antiguas de Los Toldos. Relaciones de la SAA XII:225-242.

Castro, A. y J.E. Moreno 1994. Determinación de enmangues en instrumentos líticos por medio de huellas de utilización. Palaeoetnologia 7:7-20.

Civalero, M. 1999. Obsidiana en Santa Cruz, una problemática a resolver. En Soplando en el Viento, editado por Comité Editorial de 
las Terceras Jornadas de Arqueología de la Patagonia, pp. 155-164. Universidad del Comahue/ Instituto Nacional de Antropología y Pensamiento Latinoamericano, Neuquén.

Clark, J. 1987. Politics, prismatic blades, and Mesoamerican civilization. En The Organization of Core Technology, editado por J.K. Johnson y C.A. Morrow, pp. 259-284. Westview Press, Boulder, Colorado.

Collins, M. 2002. Clovis Blade Technology. University of Texas Press, Austin.

Coronato, A., A. Rabassa, A.M. Borromei, A.M. Quatroccio y G.G. Bujalesky 1999. Nuevos datos sobre el nivel relativo del mar durante el Holoceno en el Canal Beagle, Tierra del Fuego, Argentina. Actas I Congreso Argentino de Cuaternario y Geomorfología, pp. 27-28. Santa Rosa.

Durán, V. 2004. Estudio tecno-tipológico de los raspadores del sitio El Verano. Cueva 1 (Área de La Martita). Prov. De Santa Cruz. Anales de Arqueología y Etnología 41/42:129-163.

Flegenheimer, N. y C. Weitzel 2007. Caminar sobre piedras, los artefactos fracturados de Cerro El Sombrero. Actas del XVI Congreso Nacional de Arqueología Argentina, pp. 263-267. Jujuy.

Franco, N. 2008. La estructura tecnológica regional y la comprensión de la movilidad humana: tendencias para la cuenca del río Santa Cruz. En Arqueología del Extremo Sur del Continente Americano. Resultados de Nuevos Proyectos, compilado por L.A. Borrero y N.V. Franco, pp. 119-154. Instituto Multidisciplinario de Historia y Ciencias Humanas (CONICET), Buenos Aires.

Franco, N., P. Ambrústolo y N. Cirigliano 2012. Disponibilidad de materias primas líticas silíceas en el extremo sur del Macizo del Deseado: Los casos de la Gruta y Viuda Quenzana (Provincia de Santa Cruz, Argentina). Magallania 40:279-286.

Gradin, C., C. Aschero y A. Aguerre 1979. Arqueología del área Río Pinturas, Prov. Santa Cruz. Relaciones de la Sociedad Argentina de Antropología XIII (NS):183-227.

Hermo, D. 2008. Los Cambios en la Circulación de las Materias Primas Líticas en Ambientes Mesetarios de Patagonia. Una Aproximación para la Construcción de los Paisajes Arqueológicos de las Sociedades Cazadoras-Recolectoras. Tesis de Doctorado, Facultad de Ciencias Naturales y Museo, Universidad Nacional de La Plata, La Plata.

Hermo, D. y V. Lynch 2015. Core technology from Maripe Cave site (Santa Cruz, Argentina): Implications for rocks provisioning processes and lithic production. Quaternary International 375:135144. http://dx.doi.org/10.1016/j.quaint.2014.11.063.

Hermo, D. y L. Magnin 2012. Blade and bifacial technology in Mid-Holocene occupations at Deseado Massif, Santa Cruz province, Argentina. Quaternary International 256:71-77.

Hermo, D., L. Magnin, P. Moreira y S. Medel 2015. Variabilidad y distribución de fuentes de materias primas líticas en el Macizo del Deseado (Santa Cruz, Argentina). Intersecciones en Arqueología, volumen especial "Materias Primas Líticas en Patagonia", editado por J. Alberti, K. Borrazo y V. Fernández, pp 87-100. Buenos Aires.

Kuhn, S. 1995. Mousterian Lithic Technology: An Ecological Approach. Princeton University Press, Princeton.

Lourdeau, A., S.E. Hoeltz y S.A. Viana 2014. Early Holocene blade technology in southern Brazil. Journal of Anthropological Archaeology 35:190-201.
Lynch, V. 2016. Estudio Comparativo de la Producción y Uso de Artefactos Líticos en el Macizo del Deseado (Santa Cruz, Argentina). British Archaeological Report. International Series (S2816).

Lynch, V., M. Fernández y L. Miotti 2015. Estudio experimental sobre la dinámica postdepositacional en rastros de uso: Integridad artefactual del Componente 1 de Cueva Maripe (Santa Cruz, Argentina). Magallania 43:1-19.

Lynch, V. y D. Hermo 2015. Evidence of hafting traces on lithic end-scrapers at Maripe cave site (Santa Cruz, Argentina). Lithic Technology 40:68-79.

Lynch, V. y L.L. Miotti 2016. Morphological and functional variability on the endscrapers in Cueva Maripe Site (Santa Cruz Province, Argentina). Lithic Technology 41:60-74. http://dx.doi. org/10.1080/01977261.2015.1107300

Magnin, L.A. 2011. Cuencas de captación de rocas. Una propuesta para abordar la circulación de materias primas líticas en paisajes con alta diversidad de rocas. Revista Internacional de Ciencia y Tecnología de la Información Geográfica 11:332-354.

Mansur-Franchomme, M.E. 1986-1990. Instrumentos líticos: Aspectos da análise funcional. Arquivos do Museu de Historia Natural 11, pp. 115-169. Belo Horizonte, Universidade de Minas Gerais.

Mansur, M.E. y A. Lasa 2005. Diversidad artefactual vs. Especialización funcional: análisis del IV Componente de Túnel I (Tierra del Fuego, Argentina). Magallania 33:69-91.

Menghin, O. 1952. Fundamentos cronológicos de la Prehistoria de Patagonia. RUNA 5:23-43.

Miotti, L. y L. Marchionni 2014. Autopodios de guanacos en sitios arqueológicos: equifinalidad entre lo palatable y lo preservado. Revista Chilena de Antropología 29:122-129.

Miotti, L., L. Marchionni, B. Mosquera, D. Hermo y A. Ceraso 2014. Fechados radiocarbónicos y delimitación temporal de los conjuntos arqueológicos de Cueva Maripe, Santa Cruz (Argentina). Relaciones de la Sociedad Argentina de Antropología XXXIX:509-537.

Miotti, L. y M. Salemme 2004. Poblamiento, movilidad y territorios entre las sociedades cazadoras recolectoras de Patagonia. Complutum 15:177-206.

Nelson, M. 1991. The study of technological organization. En Archaeological Method and Theory, editado por M.B.S Chiffer, pp. 57-100. University of Arizona Press, Tucson.

Odell, G.H. 1994. Prehistoric hafting and mobility in the North American Midcontinent: Examples from Illinois. Journal of Anthropological Archaeology 13:51-73.

Orquera, L. 1984-85. Tradiciones culturales y evolución en Patagonia. Relaciones de la Sociedad Argentina de Antropología 16:249-267.

Paunero, R.S. y A. Castro 2001. Análisis lítico y funcionalidad del Componente inferior de Sitio Cueva 1, Localidad Arqueológica Cerro Tres Tetas, Provincia de Santa Cruz, Argentina. Anales del Instituto de la Patagonia 29:189-206.

Paunero, R.S., A.S. Castro y M. Reyes 2007. Estudios líticos del Componente medio del Sitio Cueva 1 de cerro Tres Tetas, Santa Cruz, Argentina: implicaciones para construir patrones de distribución artefactual y uso del microespacio. En Arqueología de Fuego-Patagonia. Levantando Piedras, Desenterrando 
Huesos... y Develando Arcanos, editado por F. Morello, A. Prieto, M. Martinic y G. Bahamonde, pp. 613-622. Centro de Estudios del Cuaternario Antártico (CEQUA), Punta Arenas.

Rabassa, J. 2010. Gondwana paleolandscapes: Long-term landscape evolution, genesis, distribution and age. Geociencias 29:541-570.

Semenov, S.A. 1976. Prehistoric Technology. An Experimental Study of the Oldest Tools and Artifacts from Traces of Manufacture and Wear. Moonraker Press, Bradford-on-Avon, Wiltshire.

Shennan, S. 1992. Quantifying Archaeology. Edinburgh University Press, Edinburgh.

Skarbun, F. 2009. La Organización Tecnológica en Grupos Cazadores Recolectores desde las Ocupaciones del Pleistoceno Final al Holoceno Tardio, en la Meseta Central de Santa Cruz. Tesis Doctoral inédita, Facultad de Ciencias Naturales y Museo, Universidad Nacional de La Plata.

Stern, C.R. 1999. Black obsidian from central-south Patagonia; chemical characteristics, sources and regional distribution of artifacts. Actas de las III Jornadas de Arqueología de la Patagonia, Soplando en el viento, pp. 221-234. Instituto Nacional de Antropología y Pensamiento Latinoamericano y Universidad Nacional del Comahue, Neuquén.

Suárez, R. 2011. Movilidad, acceso y uso de ágata translúcida por los cazadores-recolectores tempranos durante la transición Pleistoceno Holoceno en el Norte de Uruguay (ca. 11.000-8.500 A.P). Latin American Antiquity 22:359-383.

Walker, W. 1995. Ceremonial trash. En Expanding Archaeology, editado por J.M. Skibo, W.H. Walker y A.E. Nielsen, pp. 67-79. University of Utah Press, Salt Lake City.

Yerkes, R.W. 1990. Using microwear analysis to investigate domestic activities and craft specialization at the Murphy site, a small hopewell settlement in Licking County, Ohio. En The Interpretative Possibilities of Microwear Studies, editado por B. Gräslund, H. Knutsson, K. Knutsson y J. Taffinder, pp. 167-176. Societas Archaeologica Upsaliensis, Uppsala. 